\title{
The global trend towards decarbonization of the economy, the introduction of the Carbon Border Adjustment Mechanism in the EU and the possible consequences for Russia
}

\author{
Vladimir Sh. Urazgaliev ${ }^{1}$, Andrey $V$. Novikov ${ }^{1}$ and Galina A. Menshikova ${ }^{1}$ \\ ${ }^{1}$ St. Petersburg State University, Faculty of Economics, Faculty of Sociology, 7/9 Universitetskaya \\ nab., St. Petersburg, 199034 Russia
}

\begin{abstract}
Research background: In the process of implementing the Paris Agreement (2015), Europe is a leader in the formation of new legislative initiatives in order to develop a set of effective measures to reduce greenhouse gas emissions in the atmosphere. The European Commission approved the European Green Deal (2015) - a strategy for achieving the EU parameters of climate neutrality through the transition to a clean circular economy. Its main goal is to reduce carbon dioxide emissions by 2030 by 50 - 55\% from 1990 levels and achieve full carbon neutrality of the EU by 2050. As part of this strategy, the Carbon Border Adjustment Mechanism (CBAM) is being developed. The introduction of CBAM means a revolutionary transformation in the system of international economic relations.

Purpose of the article is to identify and assess possible risks for producers and consumers, primarily of energy products after the introduction of CBAM, as well as the impact of these risks on Russian exports to Europe. Methods: The authors carried out a comparative analysis of scenarios for the implementation of CBAM in the sectorial and product segments of trade between Russia and the EU.

Findings: The article contains comparative assessments of the beginning redistribution of international markets in the sectoral and product coverage of emissions, as well as an analysis of the unfolding contradictions in the verification of methods for determining the carbon footprint in the production chains of the real sector of the economy.
\end{abstract}

Keywords: decarbonization; Carbon Border Adjustment Mechanism; climate neutrality

JEL Classification: $A 11 ; A 14 ; B 16$

\footnotetext{
${ }^{*}$ Corresponding author: uvsh54@yandex.ru
} 


\section{Introduction}

Serious attention to the problems of climate change on an international scale began to be paid in the mid-1980s. In 1988, with the participation of the United Nations Environment Program and the World Meteorological Organization, the Intergovernmental Panel on Climate Change (IPCC) was established. Its main task is to prepare regular assessments of scientific approaches to the problems of climate change and related risks, their prevention or control. The IPCC does not undertake its own scientific research, but summarizes scientific publications on climate issues in its Assessment Reports.

\section{Methodology, databases and analytical sources of research}

The foundations of the international climate policy proper were laid down in the Nations Framework Convention on Climate Change (UNFCC). The goal of the IPCC was to find ways to stabilize GHG concentrations in the atmosphere at a level that would prevent dangerous anthropological impact on the climate system (Perugini et al., 2021). On March 21, 1994, the UNFCCC entered into force. at the moment it has been signed by 196 countries, as well as the EU. At the third conference of the UNFCC countries on December 11, 1997 in the Japanese city of Kyoto, Kyoto Protocol was adopted and signed by 159 states, which became the first interstate agreement aimed at limiting the growth of anthropogenic GHG emissions by specific quantitative parameters. The protocol entered into force on February 16,2005 . It was ratified by 191 countries and the EU, while the US refused to ratify it. At the first stage (2008 - 2012), the countries had to reduce their GHG emissions by 5.2\% compared to 1990 levels. Each state received specific emission quotas that could be traded. China and India have not undertaken commitments in terms of emissions. The United States announced its non-participation in this protocol until 2013. The impact of the comprehensive implementation of the Kyoto Protocol on competitiveness and jobs in the United States is analyzed in the article (Krause et al., 2003).

In 2012, at the Doha conference, the Kyoto Protocol was extended until 2020. At this stage, New Zealand, Japan and Russia did not undertake quantitative commitments to reduce GHG emissions, and Canada withdrew from the protocol.

On December 12, 2015, following the results of 21 IPCC conferences, the Paris Climate Agreement (PC) was adopted by consensus. The PC was signed on April 22, 2016 by 175 countries (including Russia). Formally, the PS was supposed to replace the Kyoto Protocol upon its expiration in 2020, but due to the weakness of the latter, the PS is actually in effect from the moment it entered into force on November 4, 2016. It is currently supported by all 197 participants, including the EU IPCC, of which 189 have ratified it. Russia has not formally ratified the PS, arguing that it does not contain the grounds for ratification provided for by Russian legislation. Therefore, Russia's consent to be bound by the decisions of the PS is legally expressed in the form of its adoption. The United States left the PS on November 4, 2020, but officially returned to it in February 2021.

Unlike the Kyoto Protocol, the PC does not have a mechanism for emission quotas. Its members develop and declare at the national level contributions (Nationally Determined Contributions $\rightarrow$ NDS) to reduce GHG emissions.

On September 11, 2019, The European Green Deal (EGD) (Pollin, 2018; Moniz, 2019; Sutherland, 2020; Dale, 2021) was adopted and published the next day by the European Commission (EC), which became a roadmap for the EU's ambitious green policy to achieve $100 \%$ climate neutrality for the European economy by 2050 . The main directions of Green Deal are presented in Figures 1, as well as reflected in numerous works, see for example (Kramer, 2020; Montanarella 2020; Lee et al., 2021; Mastini et al., 2021). 

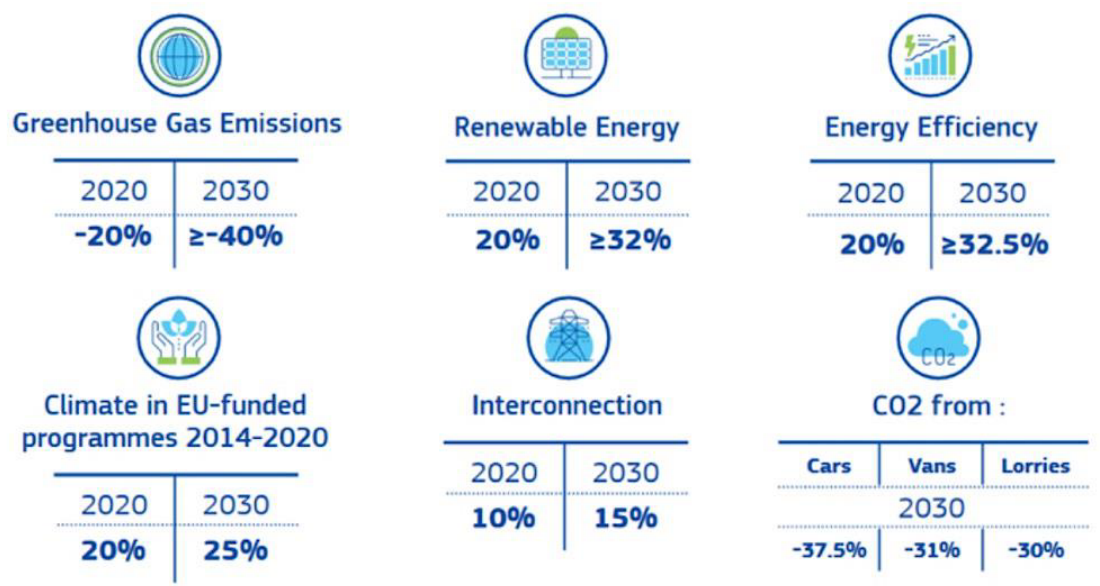

Figure 1. «Green deal» in numbers.

Source: https://ec.europa.eu/info/publications/4th-state-energy-union en

In the package of initiatives to promote the Green Deal, a key place belongs to the European GHG emissions trading system (EU ETS) (Tarnawska \& Rosiek, 2011; Borghesi,\& Flori, 2018; Rosendahl, 2019; Kim \& Park, 2021). The EU ETS, which was initiated by Directive 2003/87/EC, became operational on 1 January 2005 (COM, 2019). According to this directive, three stages were planned. At the first two stages (2005-2007 and 2008-2012), the maximum emission level was formed. At the same time, more than $90 \%$ of quotas were distributed here free of charge due to the threat of loss of competitiveness of EU exporters due to the carbon leakage effect (Perino, G., 2019; Yu et al., 2021). It is associated with the possibility of transferring production with large volumes of emissions or consumption of energy resources to other countries where there are no such payments for emissions. This does not lead to an absolute reduction in global $\mathrm{CO}^{2}$ emissions, but only to their movement between countries. For example, allocate channels for carbon leakage: the competitiveness, the energy market, the income, and the technology spillovers channel. Various counter - measures against leakage were suggested; one of them being border carbon adjustments (Lininger, 2015).

It was for the EU enterprises, vulnerable from the point of view of carbon leakage, that the free transfer of quotas for $\mathrm{CO}^{2}$ emissions was carried out. For this, benchmarks were installed. Carbon metrics based on $10 \%$ of the most efficient plants in the industry. If the enterprise exceeded the benchmark, then all emissions were covered by free quotas. They could also be obtained for regulatory defined industries most susceptible to carbon leakage (oil refining, hydrogen production in the EU, etc.) Thus, carbon trading is a system for redistributing rights to $\mathrm{CO}^{2}$ emissions from enterprises that do not fully use the governmentset quota and those enterprises that exceed the emission standards.

The third stage of development of the EU ETS system took place in 2013-2020 (Ghazani \& Jafari, 2021). "At this stage, the emission rate decreased by $1.74 \%$ annually, only $57 \%$ of the permits were managed on the basis of product benchmarks, which were calculated for 54 different products according to the principle: 1 benchmark $=1$ product".

At the fourth stage (2021-2030), there will be a rejection of the free distribution of quotas for products, a transition to $100 \%$ selling them at auctions and their annual decrease by $2.2 \%$. By mid-2021, EUETS is regulating direct emissions of carbon dioxide $\left(\mathrm{CO}^{2}\right)$, nitrogen oxide $\left(\mathrm{N}^{2} \mathrm{O}\right)$ and perfluorocarbons (PFCs), covering $40 \%$ of all EU emissions. 


\section{Results, concerning institutionalization of CBAM.}

At the beginning of the 2000s, attention to the problems of taxing carbon emissions increased in Europe (Zhang \& Baranzini, 2004) and since 2007 they turned to the possibility of introducing Border tax adjustments (BTA), which was later called CBAM (carbon border adjustment mechanism). It is based on the idea of charging fees for goods imported into the EU based on an assessment of their carbon intensity, which should also compensate for the carbon leakage effect. In 2019, the idea of CBAM became one of the components of EGD.

The final version of the CBAM appeared on July 14, 2021, when the EC published a largescale package of legislation called "Fit-for-55" in the field of climate, energy, agricultural, transport and tax policies of the EU (COM, 2021). Within this package, a specific scheme for introducing CBAM is presented on 291 pages. At the same time, a number of CBAM parameters (for example, the volume of granting free quotas for producers of carbon products that are subject to high risks of carbon leakage) were fixed in the draft normative act on the modernization of the ECT. The implementation of the CBAM includes two stages: from 2023, importers in the EU will only be accountable for the import of CBAM goods, depending on their carbon intensity, and from 2026, a payment scheme will be launched.

CBAM is based on two components - the carbon price and the carbon content of imports. In this regard, the key factors are the volumes of trade that fall under the CBAM - the regulation of goods and the volume of emissions in the production of these goods. In its most general form, the scheme of operation of CBAM is as follows:

- To regulate the work of CBAM, a special governing body is created - CBAM Authority, which will issue digital CBAM certificates, each of which represents one ton of $\mathrm{CO} 2$ emissions contained in their imported goods, and also control the collection of payments for them. Importers in the EU of CBAM products are required to purchase these certificates. Their cost will be calculated based on the average emission price at the ETS auctions for the previous week. Thus, the price of quotas in the ETS will be used for the purposes of the CBAM.

- For the import of goods into the EU by CBAM, importers will have to declare the amount of goods that they imported into the EU in the previous year, the amount of emissions associated with these goods, and present the required number of CBAM certificates by 31 May annually. In the absence of confirmation of a sufficient number of permits by May 31, importers in the EU will be fined three times the average price of CBAM certificates in the previous year for each missing certificate.

- $\quad$ EU producers will pay for carbon in ETS, and only importers of CBAM products in the EU will pay for the CBAM certificate. At the same time, the price per unit of carbon for all suppliers to the EU market will be the same. Free quotas in ETS remain, but obligations under CBAM will vary depending on the share of free quotas.

- $\quad$ Branch coverage (scope) of CBAM includes the following industries: ferrous metallurgy, non-ferrous metallurgy (aluminum), chemistry (nitrogen compounds) and the production of nitrogen fertilizers, electric power industry. When calculating the actual emissions associated with electricity, specific data on the origin of electricity are taken into account, including direct sales contracts in third countries.

- Scope of emissions. All GHG emissions (scope) are assessed in terms of three types: scope 1, scope 2 and scope 3 . scope 1 are direct emissions from the production of products at a particular enterprise. scope 2 - indirect emissions from purchased energy from other producers. scope 3 - all other emissions not controlled by the 
enterprise, including transport and subsequent use of products up to waste disposal. The EU draft law takes into account scope 1 and non-energy scope 3. At the same time, the list of indirect emissions from raw materials and semi-finished products taken into account when calculating scope 3 will be determined by a separate decree.

- $\quad$ The CBAM system provides for the possibility of a deduction for importers if the manufacturer of the goods exported to the EU has already paid the national carbon tax in his country, subject to its recognition by the authorized body of the EU.

- An enterprise can obtain the status of an EU importer only after its authorization by the CBAM Authority, provided that a number of requirements are met. For example, an importer must not violate EU customs and tax laws for five years before applying for authorization.

- Countries that have entered into an agreement to merge their emissions trading system with the EU ETS, member countries of the customs union - Norway, Switzerland, Iceland and Liechtenstein, as well as a number of dependent territories of the EU, will not be covered by the CBAM system.

\section{Results, depicting situation in Russian economy}

In Russia, after the publication of the CBAM scheme, the first calculations of direct losses of Russian exporters from the introduction of the EU carbon tax, taking into account Scope 1 and Scope 3, were made at the Institute for Problems of Natural Monopolies (IPEM) (SWAM, 2021). Estimated costs of Russian exporters on payments under CBAM are looking as follows:

- calculations only for a narrow sectoral scope

- $\quad$ payment rate of $\$ 60 / \mathrm{tCO} 2$

- taking into account the real carbon footprint of products (according to Rosstat and national emission inventory )

- $\quad$ taking into account scope 1 , as well as taking into account scope 3 for separate production chains (steel and aluminum products, nitrogen fertilizers and compounds)

- without taking into account alternative effects (loss of market share on the EC market)

- without taking into account the decrease in payments due to the preservation of free quotas in the EU ETS

In addition, indirect effects are partially taken into account (decrease in demand for electricity and heat)

- the decrease in the production of metal ores, fossil fuels, etc. is not taken into account.

According to these calculations, the tax burden on Scope 1 could amount to $\$ 1.13$ billion per year, while the cost of CO2 for the EU ETS is \$ 60, and the burden on Scope -3 is \$ 1.17 billion. At the same time, to calculate Scope -3, Scope-1 was evaluated not only for SVAMgoods (for example, cast iron and aluminum), but also for raw materials used for their production (for example, coke and alumina). In general, Russian exports in the amount of almost $\$ 9.5$ billion may fall under SBAM regulation. This is equivalent to an import duty of $24 \%$. The results of calculations are presented in Table 1.

As follows from Table 1, the main effects of CBAM for the Russian economy are:

- Direct effects (\$2,3 billion)

- Indirect effects (\$222 million Increase in the cost of production by an average of $24 \%$ (cement - almost in 2 times)

Accounting for scope 3 emissions can lead to a 10 -fold increase in CBAM payments 
(given the complexity of determining the boundaries of the chains under consideration)

\begin{tabular}{|c|c|c|c|c|c|}
\hline & \multicolumn{3}{|c|}{$\begin{array}{l}\text { Direct effects from CBAM input. } \\
\text { Additional costs of Russian } \\
\text { exporters (\$ million) }\end{array}$} & \multirow[t]{2}{*}{$\begin{array}{c}\text { Export (\$ } \\
\text { million) }\end{array}$} & \multirow{2}{*}{$\begin{array}{c}\text { The ratio of } \\
\text { additional } \\
\text { costs to } \\
\text { exports }\end{array}$} \\
\hline $\begin{array}{l}\text { Product } \\
\text { groups }\end{array}$ & Scope 1 & $\begin{array}{c}\text { Scope } \\
3\end{array}$ & Total & & \\
\hline Electricity & 305,8 & - & 305,8 & 632,8 & $48 \%$ \\
\hline $\begin{array}{c}\text { Ferrous } \\
\text { metals }\end{array}$ & 314,1 & 955,9 & 1270,0 & 4805,7 & $26 \%$ \\
\hline $\begin{array}{c}\text { Non-ferrous } \\
\text { metals }\end{array}$ & 159,6 & 145,7 & 305,3 & 2868,1 & $11 \%$ \\
\hline $\begin{array}{l}\text { Nitrogen } \\
\text { compounds }\end{array}$ & 349,4 & 0,1 & 349,5 & 495,9 & $70 \%$ \\
\hline $\begin{array}{l}\text { Nitrogen } \\
\text { fertilizers }\end{array}$ & 1,7 & 64,7 & 66,5 & 664,5 & $10 \%$ \\
\hline Cement & 2,3 & - & 2,3 & 2,6 & $87 \%$ \\
\hline Total & 1132,9 & 1166,4 & 2299,3 & 9469,6 & $24 \%$ \\
\hline
\end{tabular}

Table 1. Quantitative assessment from CBAM for the Russian economy

Note: total exports are lower than the above value of $\$ 10$ billion, because the calculations did not take into account mixed fertilizers containing nitrogen components

Source: IPEM

According to IPEM calculations, Russia ranks first in absolute terms in terms of the value of vulnerable exports to the EU (EU - $27+4$ countries of the customs union): $\$ 10$ billion (according to the CBAM bill) and $\$ 60$ billion (analogue EU ETS + mineral fertilizers). In relative terms, respectively, $2.3 \%$ (fourth place) and $14.1 \%$ (second place) among large exporters. (Fig. 2)

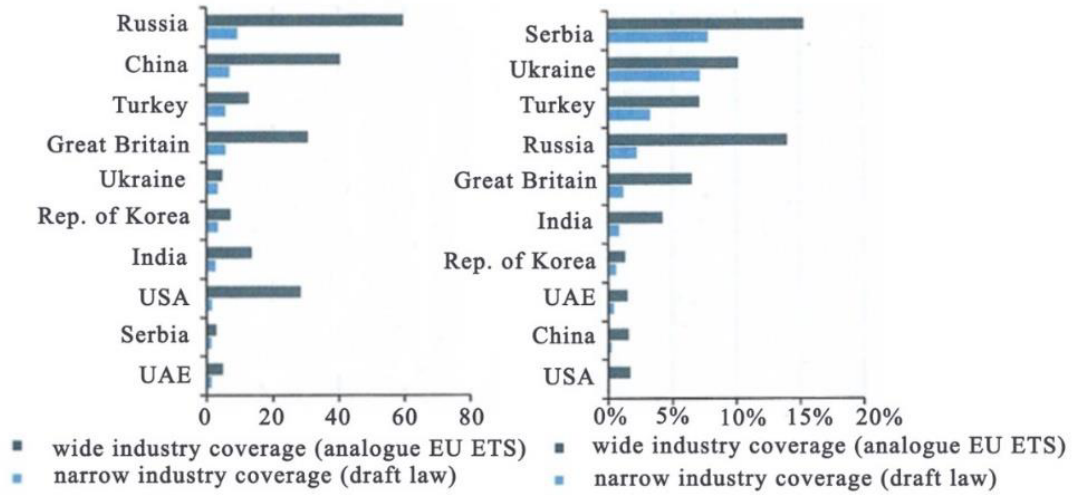

Figure 2. The volume of exports of the Air Force potentially falling under the CBAM depending on the sectoral coverage in absolute and relative terms

Source: IPEM

According to the calculations of the Russian holding - Ros Business Consulting (RBC) (RBC, 2021), according to the methodology confirmed by the Ministry of Economic Development of Russia, based on the volume of imports of Russian goods from the EU in 2020 in the amount of 6.99 billion euros (Fig. 3). the carbon tax will amount to almost 7 billion euros This is $7.3 \%$ of the value of imports of goods from Russia to the EU in 2020, 
and in physical terms -16.3 million tons (in 2019 - 18.4 million tons). Annual tax payments will amount to at least $€ 1.1$ billion (Fig. 4), which will actually be equivalent to an additional ad valorem import duty of $16 \%$ (RBK). The calculation is carried out on the basis of the physical volumes of Russian exports to the EU in 2020, the price of the EU ETS emission allowance is about 50 euros per ton and the EU benchmarks for the carbon intensity of these goods
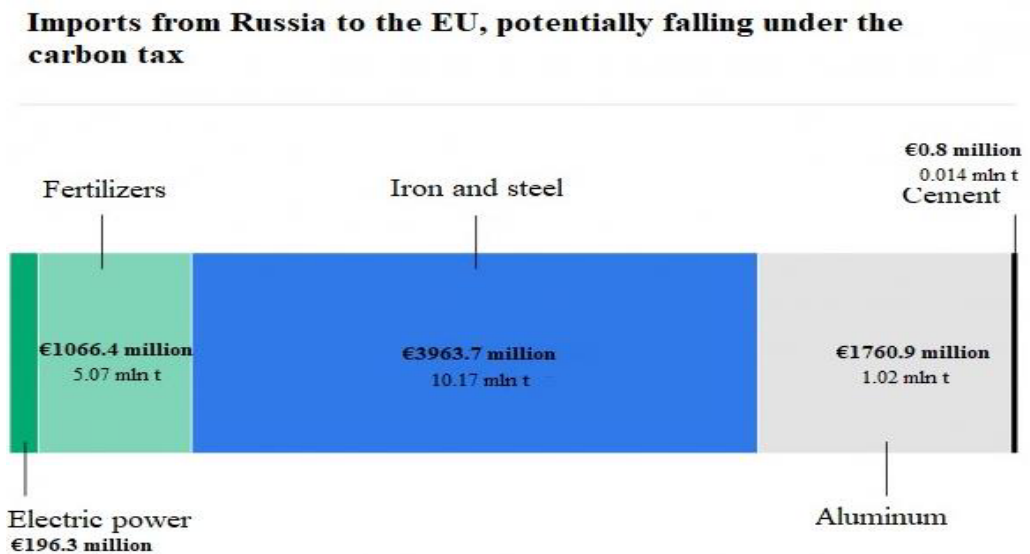

\section{TOTAL:€6.99}

Figure 3. Imports from Russia to the EU, potentially falling under the carbon tax

Source: calculations of RBC, European Commission, Eurostat

\section{Amount of carbon tax payable}

Russia, 2020

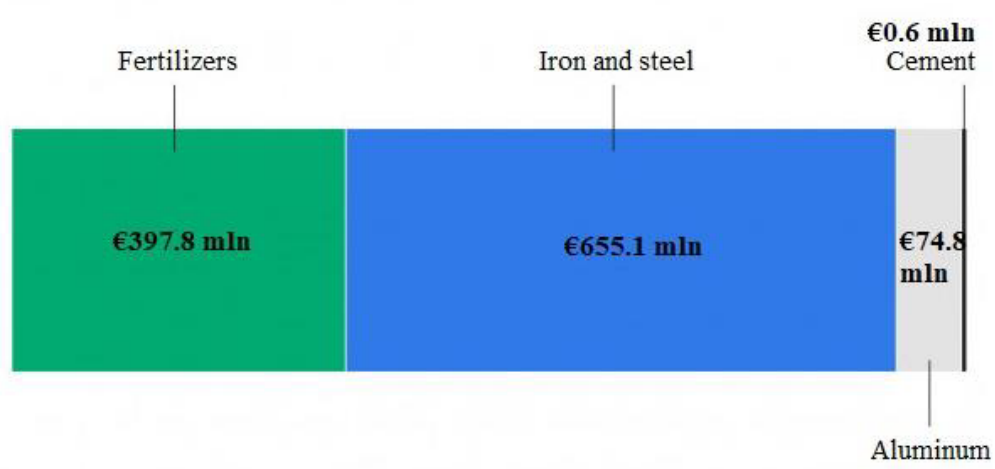

Figure 4. Amount of carbon tax payable

Source: calculations of RBC, European Commission, Eurostat

According to RBC, Russia's annual losses from the export of SWAM-goods to the EU (1.13 billion euros) will be almost equal to the total losses of the next in the list of Turkey, Ukraine and the UK (1.18 billion euros) (fig. 5) 


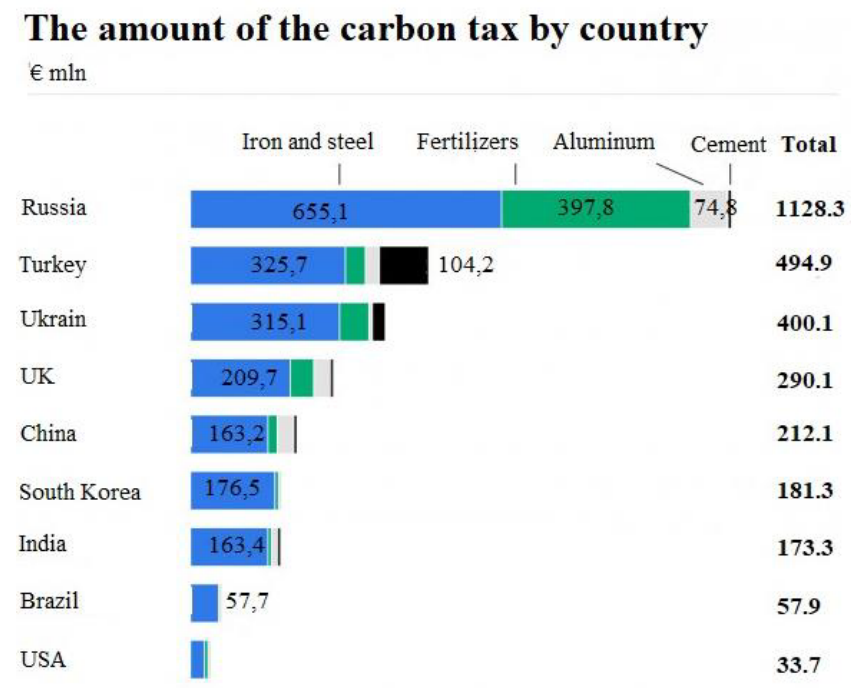

Figure 5. The amount of the carbon tax by country

Source: calculations of RBC, European Commission, Eurostat

\section{Conclusions}

Over the past 2-3 years, the efforts of the world community (primarily the EU) to create a legislative and regulatory framework to accelerate the processes of decarbonization of the economy have sharply intensified. The turning point here is the adoption by the EU of a package of legislation called "Fit-for-55" in the field of climate, energy, agricultural, transport and tax policies. In this package, the most important place belongs to the bill for the introduction of $\mathrm{CB}+\mathrm{AM}$, which should actually start working in 2026. The main goal of CBAM is to prevent carbon leakage, which will help to launch a competitive race to reduce the carbon intensity of the economy.

Preliminary calculations of losses of Russian exporters from the introduction of CBAM show that, on the whole, they are not critical for Russia. But when carrying out such calculations, serious problems arise with assessing the indirect effects of such regulation. For example, due to a possible decrease in the export of CBAM-goods, Russia is threatened not only with the loss of export niches, but also with the loss of demand within Russia for electricity and heat, which, in turn, along the chain will lead to losses in the oil and gas production and coal industries, in oil refining, ore mining, etc.

When Scope 2 is included in the regulation and all imports of goods involved in the EU ETS fall under the CBAM, the magnitude of threats to Russian exports increases significantly. It is not yet clear what the internationally accepted methodology for verifying actual emissions will look like in the future, what will be the dynamics of the carbon price, what risks for the world economy will be brought by the developed schemes of energy transition to carbon-free energy sources (wind and solar energy, green hydrogen, etc.). as well as the already emerging contradictions in changing approaches to financing through investment schemes EGS and many other problems. Answers to some of them will appear in the process of analyzing the reporting of CBAM importers until 2026, when importers will only report without payment of payments. Obviously, at this stage, certain changes and adjustments to this system will be identified, and from 2026 we will see the effectiveness of the CBAM in practice. 


\section{References}

1. Borghesi, S., Flori, A. (2018) EU ETS facets in the net: Structure and evolution of the EU ETS network. Energy economics, 75, 602-635.

2. COM (2019, November 30). 640 final. Communication from the Commission to the European Parliament, the EuropeanCouncil, the Council, the European Economic and Social Committee and the Committee of the Regions. The European Green Deal. I European Commission. [Online] https://eur-lex.europa.eu/legal-content/EN/TXT/ ?qid=1596443911913\&uri=CELEX:52019DC0640

3. COM (2021, August 31). 564 final. Proposal for a REGULATION OF THE EUROPEAN PARLIAMENT AND OF THE COUNCIL establishing a carbon border adjustment mechanism (Text with EEA relevance) $\{\operatorname{SWD}(2021) 643$ final $\}-\{\operatorname{SWD}(2021) 644$ final $\}-$ $\{\mathrm{SWD}(2021) 647$ final $\}$ - $\{\mathrm{SEC}(2021) 564$ final $\}$ European Commission. [Online] https://ec.europa.eu/info/sites/default/files/carbon_border_adjustment_mechanism_0.p $\underline{\mathrm{df}}$

4. Dale, G. (2021). Karl Polanyi, the New Deal and the Green New Deal. Environmental Values, 30(5), 593-612.

5. Ghazani, M. M., \& Jafari, M. A. (2021). The Efficiency of CO2 Market in the Phase III EU ETS: Analyzing in the Context of a Dynamic Approach.

6. Kim, J., Park, K. (2021). Improving liquidity in emission trading schemes. Journal Of Futures Markets, 41(9), 1397-1411.

7. Kramer, L. (2020). Planning for climate and the environment: the EU green deal. Journal for European Environmental \& Planning Law, 17(3), 267-306.

8. Krause F. De Canio S.J. Hoerner J.A. (2003). Cutting carbon emissions at a profit (part II): Impacts on U.S. competitiveness and jobs. Contemporary Economic Policy: 21(1), 90-105.

9. Lee, T., Kim, M., Chifamba, N. (2021). Political Framework of Green New Deal: A comparative analysis of the EU and US proposals. Korean Journal of International Studies, 19(2), 221-246.

10. Lininger, C. (2015). Unilateral climate policies: the theoretical economic background. In Consumption-Based Approaches in International Climate Policy (pp. 53-61). Springer, Cham.

11. Mastini, R., Kallis, G., Hickel, J. (2021). A Green New Deal without growth? Ecological Economics, 179, 106832.

12. Montanarella, L. (2020). Soils and the European Green Deal. Italian Journal of Agronomy, 15(4), 262-266.

13. Moniz, E. J. (2019). Innovating a Green Real Deal. Science, 364(6445), 1013.

14. Perino, G. (2019). Reply: EU ETS and the waterbed effect. Nature Climate Change, 9(10), 736-736.

15. Perugini, L., Pellis, G., Grassi, G., Ciais, P., Dolman, H., House, J.I., Peters, G.P., Smith, P., Gunther, D., Peylin, P. (2021). Emerging reporting and verification needs under the Paris Agreement: How can the research community effectively contribute? Environmental Science \& Policy, 122, 116-126.

16. Pollin, R. (2018). De-growth vs a green new deal. New Left Review, (112), 5-25.

17. RBC (2021, August 31). Russia will pay the EU $€ 1.1$ billion a year in carbon tax [Online] https://www.rbc.ru/economics/26/07/2021/60fac8469a7947d1f4871b47 
18. Rosendahl, K. E. (2019). EU ETS and the waterbed effect. Nature Climate Change, 9(10), 734-735.

19. Sutherland, B. R. (2020). Financing a Green New Deal, Joule, 4(6), 1153-1155.

20. SWAM (2021, August 31): now officially. Possible effects for Russia (2021) Institute for Natural Monopoly Problems [Online] http://www.ipem.ru/files/20210726 doklad_cenef.pdf

21. Tarnawska, K., Rosiek, J. (2011). The Impact of the European Emissions Trading Scheme (EU ETS) on the EU Socio-Economic Development, Inted2011: $5^{\text {th }}$ International Technology, Education and Development Conference, 855-864.

22. Yu, BY., Zhao, QY., Wei, YM. (2021). Review of carbon leakage under regionally differentiated climate policies. Science Of the Total Environment, 146765.

23. Zhang, Z.X., Baranzini, A. (2004). What do we know about carbon taxes? An inquiry into their impacts on competitiveness and distribution of income. Energy Policy, 32(4), 507-518. 